\title{
The Choice of the Best Surgery After Single Level Anterior Cervical Spine Discectomy: A Systematic Review
}

\author{
Ricardo Vieira Botelho ${ }^{*}, 1,2,3$, Yuri dos Santos Buscariolli ${ }^{2}$, Marcus Vinicius Flores de Barros \\ Vasconcelos Fernandes Serra ${ }^{3}$, Marcia Nogueira Pires Bellini ${ }^{3}$ and Wanderley Marques Bernardo ${ }^{4}$ \\ ${ }^{I}$ Spine surgery Service-Hospital do Servidor Público do Estado de São Paulo-São Paulo, Brazil \\ ${ }^{2}$ Faculdade de Medicina-Universidade Cidade de São Paulo (UNICID)-São Paulo-Brazil \\ ${ }^{3}$ Conjunto Hospitalar do Mandaqui-São Paulo, Brazil \\ ${ }^{4}$ Brazilian Medical Association. Guidelines Project and University of São Paulo-São Paulo, Brazil
}

\begin{abstract}
Background: The anterior cervical discectomy (ACD) is often used to treat spinal cord and nerve root compressions and the frequent use of interbody fusion (ACDF) has popularized it as a common practice associated or not with cages or plates for maintaining the intervertebral disc height.

Objective: The aim of this study is to clarify the effectiveness of ACD compared with ACDF, with or without the use of anterior cervical spacer (Cage) or instrumentation with plate fixation (ACDFI).

Methods: randomized controlled trials or quasi-randomized trials were selected for analysis in one segmental level. The comparison criteria were the rates of success and failure with surgery (Odom's' criteria), fusion rates and kyphosis rates. Electronic search was made in the MEDLINE database (Pubmed), in the Central Registry of randomized trials of Cochrane database and EMBASE.

Results: Seven studies were selected for analysis.

Conclusion: Implications for practice: There is moderate evidence that clinical results of ACD and ACDF are not significant different. There is moderate evidence that addition of intervertebral cage enhance clinical results. There is moderate evidence that anterior cervical plate does not change the clinical results of ACD.

There is moderate evidence that ACD produce more segmental kyphosis than ACDF and ACDFI, with use of cage or plate.There is moderate evidence that ACD produce lower rate of fusion than ACDF and than the cages. There is limited evidence of the lower capacity of PMMA to produce fusion. There is limited evidence that fused patients have better outcome than non fused patients.
\end{abstract}

Keywords: Diskectomy, cervical spine, surgery, meta analysis.

\section{INTRODUCTION}

The anterior cervical discectomy (ACD) is often used to treat spinal cord and nerve root compressions resistant to conservative treatment. The frequent use of interbody fusion (ACDF) has popularized it as a common practice associated with discectomy, using or not disc spacers (CAGE) or cervical plate for maintaining the intervertebral disc height, to prevent spine misalignments or to correct segmental spinal kyphosis [1].

Though quoted in numerous articles that arthrodesis is the standard surgery associated with anterior cervical discectomy, some studies report good results with the isolated cervical discectomy [2].

While a great part of the best available evidence suggests there are, until now, no reasons to change from more

*Address correspondence to this author at the Spine surgery serviceHospital do Servidor Público do Estado de São Paulo-São Paulo, Haberbeck Brandão 68-92, 04027040, Brazil; Tel: 5511 55727576;

Fax: 551132762964; E-mail: bitbot@uol.com.br traditional surgeries in cervical spine to cervical arthroplasty, we intend to study the literature recommendations for surgery after anterior cervical spine discectomy (ACD) [3-5].

The aim of this study is to clarify the effectiveness of ACD compared with ACDF, with or without the use of anterior cervical spacer (Cage) or instrumentation with plate fixation (ACDFI).

\section{METHODS}

Criteria for selecting studies for this review:

\section{Types of Studies}

Randomized controlled trials or quasi-randomized trials were selected for comparing ACD with ACDF, associated with or without a Cage, with or without fixation (ACDFI) in one segmental level. Then, the primary study should compare ACD with any other surgical technique when treating one level cervical spine disease. 


\section{Types of Participants}

Adult patients from any gender, with myelopathy or nerve root symptoms and signs did not respond to an initial conser-vative therapy, associated with soft or hard disc herniation, with or without osteophytes, in a single vertebral level disease. The papers describing interventions in one and more levels were included only if it was possible to identify that the therapeutic results were separately described for one and more levels.

\section{Types of Intervention}

We selected controlled trials that compared discectomy alone (ACD) with ACDF in one intervertebral disc space, with or without the use of disc spacer or ACDFI. Quasirandomized studies were included only if there were less than five randomized trials evaluating one specific outcome [6].

\section{Kinds of Measures of Outcome}

The comparison criteria were determined as the rates of success and failure with surgery, described in terms of the intensity of symptoms, limitation on activities of daily living and work (Odom's criteria [7]), fusion rates and kyphosis rates. Returning to work was not studied due to it being subjected to greater intercultural variation, mainly between different countries.

\section{The Method for Identification of Studies}

Electronic search was made in the MEDLINE database (PubMed), in the Central Registry of randomized trials of Cochrane database (CENTRAL) and EMBASE.

The following search strategies were used with the following descriptors (up to August 2011).

\section{MEDLINE SEARCH}

1\#(“discectomy"[Mesh Terms] OR "diskectomy"[All Fields] OR "diskectomy"[All Fields] OR "spinal fusion" [MeSH Terms] AND ("cervical vertebrae" [MeSH Terms] OR "cervical vertebrae"[All Fields] OR "cervical spine" [All Fields]) AND ("intervertebral disk displacement"[MeSH Terms] OR ("intervertebral" [All Fields] OR "intervertebral disk displacement"[All Fields] OR ("disc" [All Fields] AND "prolapse" [All Fields]) OR "disc prolapse" [All Fields]))-1016.

2\#"Cervical Vertebrae"[Mesh] AND ("Random Allocation" [Mesh] OR "Randomized Controlled Trial "[Publication Type])-427.

\section{EMBASE SEARCH}

\# Cervical Spine and Randomized controlled Trial-207.

\section{CENTRAL COCHRANE OF RANDOMIZED TRIALS SEARCH}

\# Cervical spine- 655 .

\section{Study Selection}

One of the authors conducted the electronic search. Two authors independently assessed the articles by titles and abstracts and selected those related to the search. The disagreements in the selection of studies were resolved by discussion among authors. Screening references given in relevant systematic reviews and identified RCTs were searched, as well as the Citation tracking. The isolated papers were searched for related publications and the bibliographic citations of selected papers were searched. Personal communications with content experts in the field were searched among authors specialized in spine surgery.

\section{Statistic}

The individual and pooled findings were described as Odds ratio, Log Odds Ratio and Log risk ratio. The significance of the result was expressed as a confidence interval or a probability of type I error (p). Statistical heterogeneity of the results was assessed using the Cochran $\mathrm{Q}$ test and test I2. The software used in the meta-analysis was "comprehensive meta-analysis" (Biostat Copyright 1998-2005, inc).

The judgment on the strength of the evidence on each comparison was based on the recommendations on Levels of Evidence [6]: RCTs

Strong - consistent findings among multiple high quality

Moderate - consistent findings among multiple low quality RCTs and/or one high quality RCT

Limited - one low quality RCT

Conflicting - inconsistent findings among multiple RCTs

No evidence from trials - no RCTs.

The potential to pool results was dependent on the comparability of the individual studies, i.e., identical treatments and outcome measures were used, sufficient detail was given to describe the selection criteria and other external validity criteria.

\section{Results}

The literature search identified 655 papers described as randomized clinical trials, in humans. The closed evaluation resulted in eight randomized or quasi-randomized studies comparing ACD with some form of arthrodesis (ACDF) or spacer (CAGE) with or without anterior plate (ACFI) (Table 1).

\section{Data Collection and Analysis}

\section{Description of Studies}

Seven studies [2, 8, 3-9] compared randomly isolated discectomy with arthrodesis with autologous bone graft, methylmethacrylate, and titanium spacer (Cage), with or without the use of anterior plate fixation. One paper (Oktenoglu [14]) compared 20 patients in a Quasirandomized trial (Heads or tail-coin) with independent assessment of the results by physical therapists and physiatrists.

Savolainen [2], Xie [8] and Oktenoglu [14] compared discectomy with discectomy and arthrodesis with bone graft and discectomy, bone graft and plate.

Vanderbent [9] compared discectomy with Polymethylmethacrylate as disc spacer.

Hauerberg [10] Compared discectomy with a titanium cage spacer. 
Table 1. Description of Compared Surgical Techniques Described by Respective Authors

\begin{tabular}{|c|c|c|c|c|c|c|c|c|}
\hline Author & N & FN & M/F & Age & \multicolumn{4}{|c|}{ Compared Surgical Techniques } \\
\hline \hline Savolainen & 91 & 86 & $63 \mathrm{~m} / 23 \mathrm{f}$ & 47,86 & Disc & Bone graft 1 & & Plate 1 \\
\hline Xie-Hulbert & 45 & 42 & $28 \mathrm{~m} / 14 \mathrm{f}$ & 42,76 & Disc & Bone graft 1 & & Plate 2 \\
\hline Van der bent & 83 & 81 & $65 \mathrm{~m} / 16 \mathrm{f}$ & 47 & Disc & & & PMMA \\
\hline Hauerberg & 88 & 79 & $43 \mathrm{~m} / 43 \mathrm{f}$ & Median & Disc & & cage Tit & \\
\hline Oktenoglu & 20 & 20 & $11 \mathrm{~m} / 9 \mathrm{f}$ & 40,5 & Disc & Bone graft 2 & & Plate 3 \\
\hline Rosenorn & 63 & 63 & $40 \mathrm{~m} / 23 \mathrm{f}$ & 51,5 & Disc & Bone graft 3 & & \\
\hline Martins & 51 & 51 & $*$ & 46,4 & Disc & Bone graft 3 & & \\
\hline Barlocher & 125 & 123 & $74 \mathrm{~m} / 51 \mathrm{f}$ & 50,5 & Disc & Bone graft 4 & Cage Tit & PMMA \\
\hline Total & $\mathbf{5 8 4}$ & $\mathbf{5 4 5}$ & $\mathbf{3 2 4} / \mathbf{1 7 9}$ & $\mathbf{4 6 , 6 5}$ & & & \\
\hline
\end{tabular}

$\mathrm{N}$ rand=number of randomized patients at beginning. $\mathrm{FN}=$ Number of studied patients. $\mathrm{M} / \mathrm{W}$ : male/woman proportion. Bone graft: 1:Smith-Robinson technique; 2:Tricortical bone Cage; 3:Cloward;4:Autologous bone graft. Cage Tit: Titaneum cage; PMMA: Polimethylmetacrilate; Plates (as described) 1: Caspar plate;2: Codman;3: Semirigid plate.*Data originally described as median.

Rosenorn [11] and Martins [12] Compared ACD with ACDF with bone graft.

Barlocher [13] compared four techniques of discectomy, bone graft, titanium cage and polymethylmethacrylate.

The studies and their types of surgery are described in Table 1. The most common clinical outcome used was Odom's scale (Table 2). The outcomes studied are displayed in Table 3.

Table 2. Odom's Criteria

\begin{tabular}{|c|c|}
\hline Rating & Odom's Criteria \\
\hline \hline Excellent & No complaints referable to cervical disc disease \\
\hline Good & $\begin{array}{r}\text { Intermittent discomfort related to cervical disease } \\
\text { but not significantly interfering with work }\end{array}$ \\
\hline Satisfactory & Subjective improvement but physical activities limited \\
\hline Poor & $\begin{array}{r}\text { No improvement or worse compared with the } \\
\text { condition before the operation }\end{array}$ \\
\hline
\end{tabular}

Five authors described the post operative kyphosis as a percentage of kyphotic patients or as a percentage of slight kyphosis or as a range of kyphosis in grades. Five papers described the fusion rates.

Three papers described differently the differences in rates of neck and arm pain (Table 3 ).

\section{Risk of Bias in Included Studies}

Seven papers were described as randomized but Oktenoglu's paper [14] was described as Quasi-randomized by lottery coin. Xie [8], Van Der Bent [9], Hauerberg [10], described the randomization methods. Rosenorn [11] described his work only as "lottery style" (Table 4).

All papers but Oktenoglu [14] described their work as randomized. Xie [8] and Hauerberg [10] made randomization by computer program. Xie [8] and Van Der Bent [9] used some kind of patients, derived outcomes or semi-analog scale in some but not all outcomes. Oktenoglu's paper [14] the final evaluation was made by blinded physiotherapist or Rheumatologist.

Only the paper of Savolainen [2] evaluated patients for 4 years; Only the paper by Martins [12] had a loss of follow up greater than $20 \%$ in clinical outcomes. In this search, only $45 \%$ had one year of follow up.

Table 3. Outcomes Studied by Each Paper

\begin{tabular}{|c|c|c|c|c|c|c|c|}
\hline & Author & FU(Year) & \multicolumn{5}{|c|}{ Studied Outcomes } \\
\hline 2 & Xie-Hulbert & 2 & & $\% \S$ & $\%$ Fusion & & $\%$ absense \\
\hline 3 & Van der Bent & 2 & & & \%Fusion & & \\
\hline 5 & Oktenoglu & 1,5 & & & $\%$ Fusion & & Difference distribution \\
\hline 6 & Rosenorn & 1 & Odom's & & & $\%$ & \\
\hline 7 & Martins & $1 / 2$ & Odom's & $\%$ & & & \\
\hline 8 & Barlocher & 1 & Odom's & Range & \%Fusion & $\%$ & $\%$ Improvement \\
\hline
\end{tabular}

Neck \& Arm pain: \% absence: Percentage of patients free of pain; Difference distribution: Statistical difference between distribution of pain between techniques. 
Table 4. Risk of Bias in Included Studies

\begin{tabular}{|c|c|c|c|c|c|}
\hline $\mathbf{A U}$ & $\begin{array}{l}\text { Adequate Sequence } \\
\text { Generation? }\end{array}$ & A C & $\begin{array}{c}\text { Blinding? Patient-Reported } \\
\text { Outcomes }\end{array}$ & Blinding? & $\begin{array}{c}\text { Incomplete Outcome Data } \\
\text { Adressed? Short Term Outcomes? }\end{array}$ \\
\hline Savolainen & Yes.1. Probably done & No & No & No & $\begin{array}{l}96 \% \text { clinical FU } 4 y \\
78 \% \text { radiologic FU. }\end{array}$ \\
\hline Xie-Hulbert & Yes.2. Probably done & No & $\begin{array}{l}\text { Two out of all outcomes are } \\
\text { pts derived outcome }\end{array}$ & No & $93 \%$ clinical FU $2 y$ \\
\hline Van der bent & yes.3. Probably done & No & pts using semianalogue scale & No & $\begin{array}{l}91 \% \text { radiologic FU } \\
96 \% \text { clinical FU }\end{array}$ \\
\hline Hauerberg & Yes. 4. Probably done & No & No & No & $89 \% 24 \mathrm{~m}$ clinical FU \\
\hline Oktenoglu & 5. Quasi-randomised & No & & No?-Blind analysis et end. & $100 \% 18 \mathrm{~m}$ clinical FU \\
\hline Rosenorn & yes. 6. Probably done & No & & No & $95 \% 12 \mathrm{M}$ clinical FU \\
\hline Martins & Yes. 7. Probably done & No & No & No & $45 \% 1 \mathrm{Y}$ clinical FU \\
\hline Barlocher & Yes.8. Probaly done & No & $\begin{array}{l}\text { Only Radiographs were reviwed } \\
\text { by independent radiologist. }\end{array}$ & No & $98,5 \% 1$ y FU \\
\hline
\end{tabular}

AC: Allocation Concealment.

1. Randomization was conducted after the selection of the surgeon;2: computer generation matrix;3: a block restricted method using sealed envelopes. $4: 150$ codes generated by computer;5:quasi-randomised(head or tail-coin);6:described as randomized; 7:described as "lottery style";8:Described as randomized.

The average of percentage of follow-up was $88.26 \%$ for all cases.

\section{Effects of Interventions}

\section{Discectomy Alone Versus Discectomy and Interbody Fusion with Bone Graft}

Five papers compared the success rate obtained with discectomy and with discectomy and fusion using Odom's scale. Patients with excellent and good outcomes were deemed as success. The calculated pooled Odds ratio for success between discectomy versus fusion is $0.855(0.476-$ 1,536) $\mathrm{p}=0.6$ (random model). There was no significant difference in this clinical evaluation between both techniques (Fig. 1).

\section{Discectomy Alone Versus Discectomy and Titanium Cage}

Hauerberg [10] and Barlocher studied the success rate (Odom's) between discectomy and titanium cage. In the Barlocher study, patients under discectomy alone had $75.5 \%$

\section{ODOM Discectomy x Fusion}

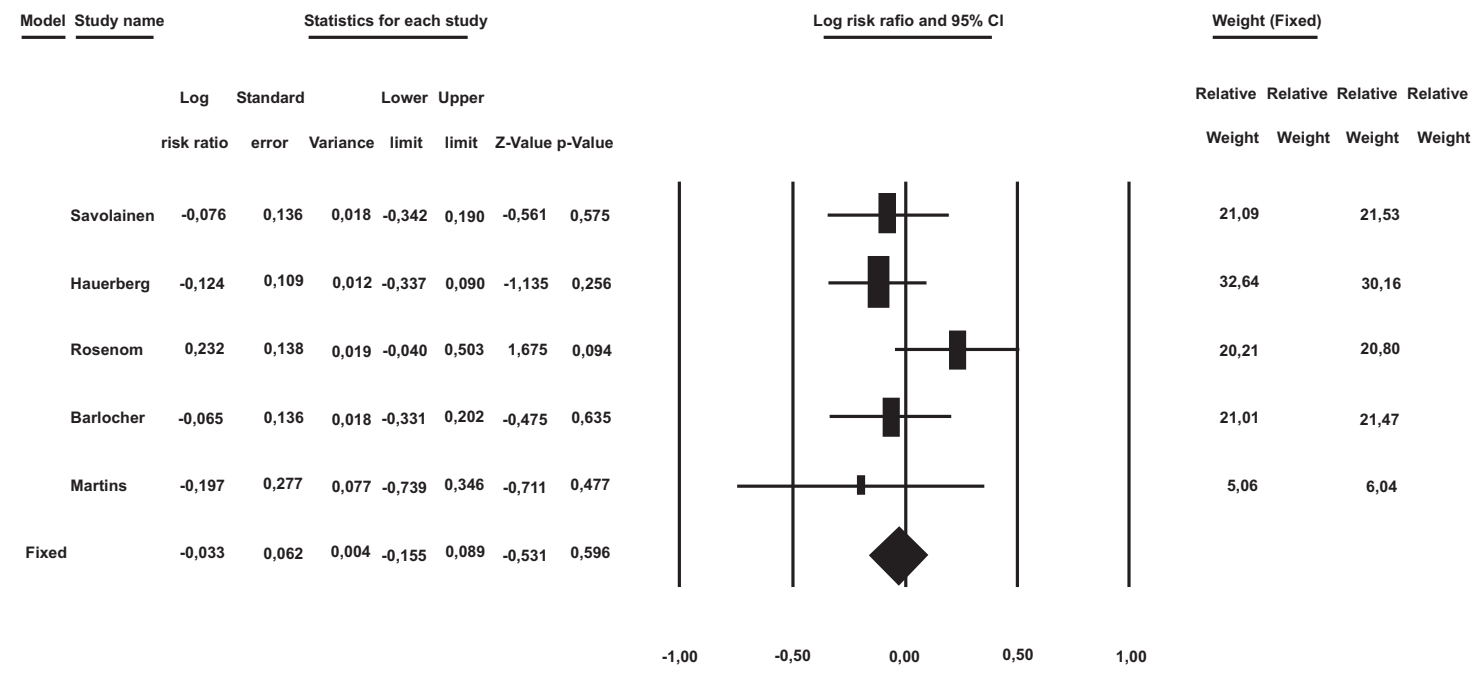

Favours Fusion Favours Discectomy

Fig. (1). Comparison between Discectomy alone versus discectomy and interbody fusion with bone graft. Outcome: Log risk ratio of success rate (Odom's scale). 


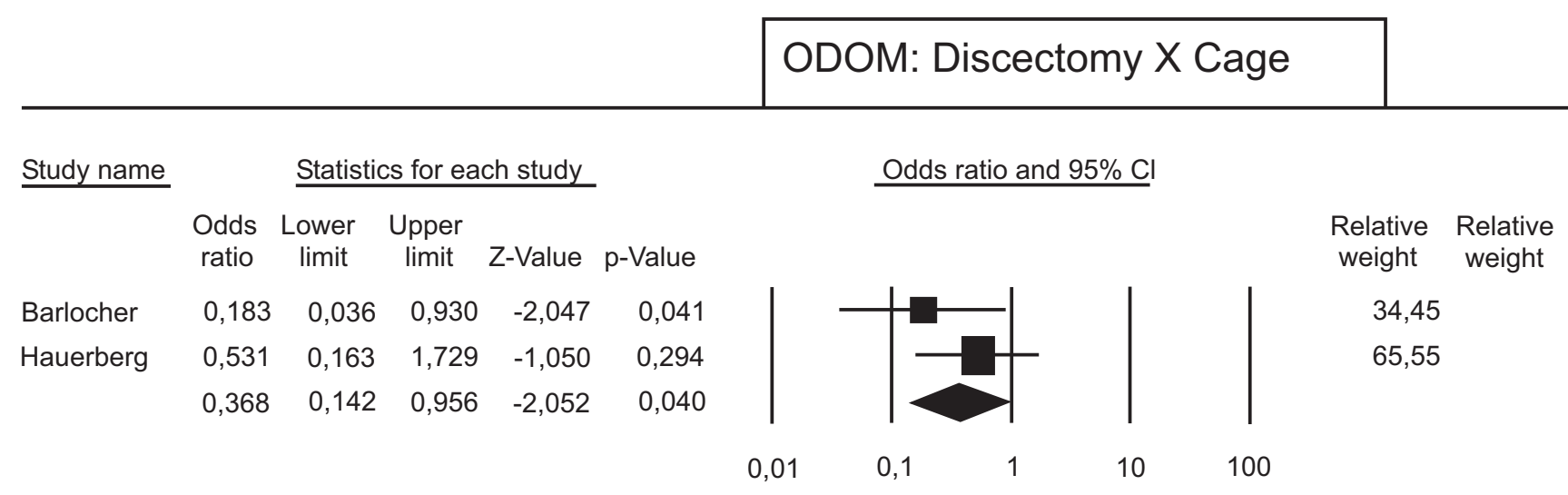

\section{Favours Cage Favours Discectomy}

Meta Analysis

$Q=1,083 ; p=0,29 . I^{2}=7,664$

Fig. (2). Comparison between Discectomy alone versus discectomy and interbody fusion using titanium cage. Outcome: Odds ratio of success rate (Odom's scale).

of success rate $(\mathrm{N}=33)$ and under discectomy followed by titanium cage, success rate was $94 \%(\mathrm{~N}=36)$. In Hauerberg's study, patients under discectomy alone had $76.7 \%$ of success $(\mathrm{N}=43)$ and $86.1 \%$ in cage group $(\mathrm{N}=36)$. The calculated pooled odds ratio for success between discectomy and fusion was $0.368(0.142-0.956 ; \mathrm{p}=0.040)$, favoring the use of titanium cage (Fig. 2).

\section{Discectomy Alone Versus Polymethylmethacrylate (PMMA) as Spacer}

Barlocher used Odom's scale to compare discectomy and PMMA as a spacer or a way to get indirect fusion. There was no clinical difference between the techniques.

\section{Discectomy Alone Versus Discectomy and Interbody Fusion Associated with Anterior Plate}

Savolainem used Odom's scale to compare discectomy and fusion using a plate. There was no difference in clinical status after 4 years follow-up.

\section{Postoperative Kyphosis}

Savolainen, Xie, Hauerberg [10], Martins and Barlocher studied postoperative kyphosis (Fig. 3).

In the Xie results, there was $75 \%$ of segmental kyphosis after ACD. These results were significantly different from the results from fusion and plate $(p=0.03)$ but individual data was not available out of the graphics to be evaluated.

Barlocher [12] described that the average range of kyphosis in their 4 comparative groups. There was $24.2^{\circ}$ in ACD, $3.3^{\circ}$ in ACDF, $12.5^{\circ}$ in PMMA and $2.7^{\circ}$ after use of plate. Data from papers by Xie and Barlocher could not be pooled together.

Savolainen [2] described that they had given special attention to the eventual kyphosis of even the slightest degree and compared the number of patients (and proportion) of even slightest Kyphosis between groups.

Hauerber [10] described the number and percentage of patients in each group with increased kyphosis.

Martins [12] classified spine alignment as excellent if lordosis was preserved, good if there was loss of lordosis $<5^{\circ}$, fair and poor where kyphosis was $>5^{\circ}$. They described the percentage of patients (as well as the number of patients in each group).

We've pooled and compared the number of patients with slight kyphosis (Sovolainen), increased kyphosis (Hauerberg ${ }^{10}$ ) and kyphosis $>5^{\circ}$ (Martins ${ }^{14}$ ) in both groups (discectomy or fusion) to evaluate the effect size of each treatment in all three papers (Fig. 3). In Savolainem study, $62 \%$ of discectomy group had slight Kyphosis $(\mathrm{N}=24)$ in comparison with $40 \%$ of patients under fusion with bone graft $(\mathrm{N}=22)$, after 4years of follow-up. In Hauerberg's and Martin's studies, $29 \%$ and $12 \%$ of patients under discectomy had some kind of Kyphosis ( $\mathrm{N}=42$ and 26, respectively), while only 22 and $4 \%$ of patients under interbody fusion had kyphosis ( $\mathrm{N}=36$ and 25, respectively) (Odds ratio=1,94; $\mathrm{p}=0,078$ ) (Fig. 3).

\section{Fusion Rates}

Four papers studied the fusion rates between ACD and ACDF techniques (Sovalainen, Xie, Van Der Bent and Barlocher [13]) (Fig. 4).

Only the paper of Sovalainen ${ }^{2}$ compared results after 4 years follow-up. There was $100 \%$ fusion rate in Discectomy only, in fusion group and Caspar plate group, without any difference between them.

Van Der Bent studied ACD compared to Polymethylmethacrylate to produce solid fusion. In 22 of the 


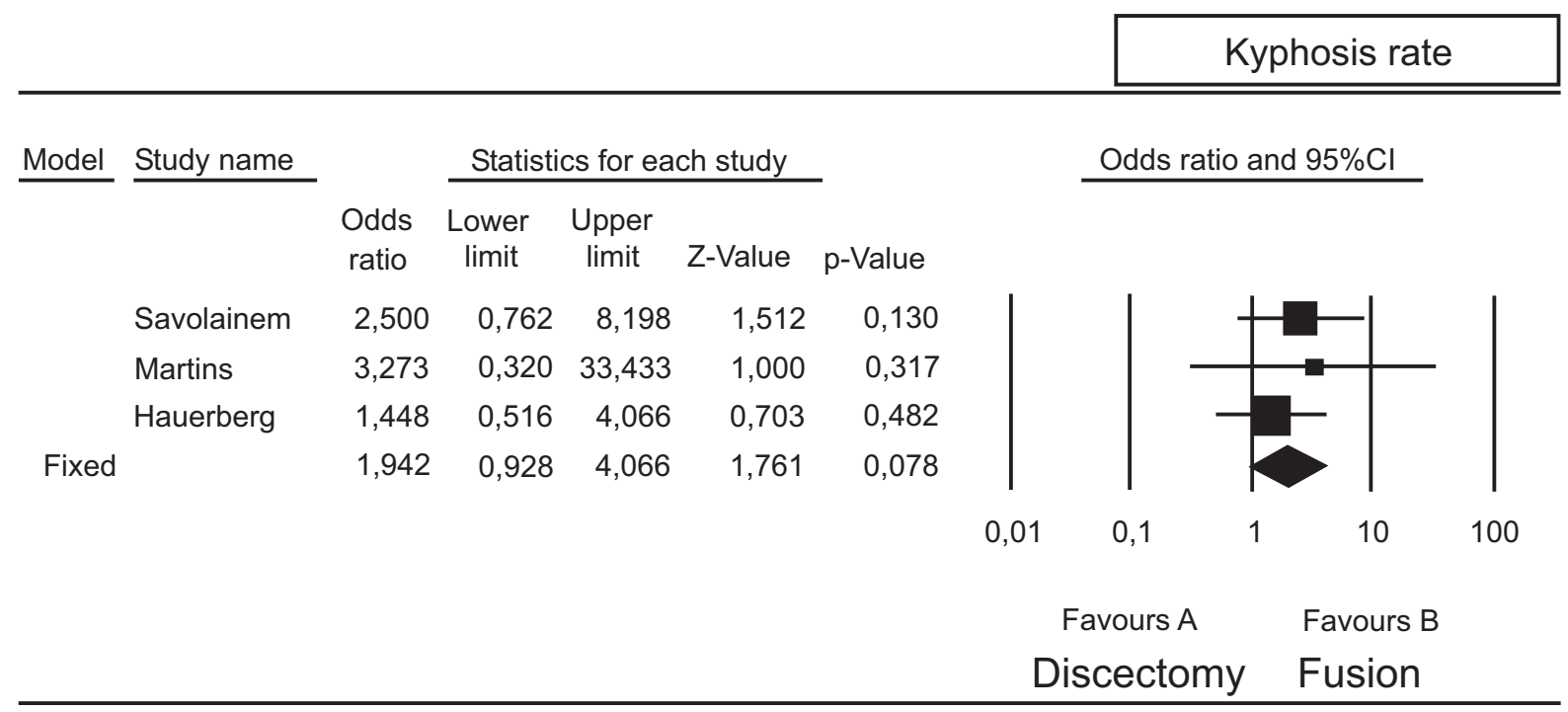

Meta Analysis

$$
Q=0,678 ; p=0,71 \cdot 1^{2}=0,000
$$

Fig. (3). Comparison between kyphosis rate between ACD and ACDF. Outcome: Odds ratio: presence of Kyphosis.

35 patients $(63 \%)$ treated with only ACD compared to only 11 of 39 of the patients $(28 \%)$ treated with polymethylmethacrylate, fusion was accomplished. A good result was observed in $84 \%$ of the patients with solid fusion, compared with $65 \%$ of those without solid fusion $(p=0.06)$.

Barlocher compared fusion rates between ACD and autologous bone graft, PMMA and titanium cage. The fusion rates were 93.3, 93.3, no fusion and 97.2\%, respectively. The titanium cage has produced the highest rate of fusion and PMMA produced no fusion.

\section{DISCUSSION}

Since 2002 cervical arthroplasty has emerged as a promising technique to be used after anterior cervical discectomy [15]. The main argument favoring this technique was a decrease in the number of adjacent level diseases after fusion. One randomized trial comparing the adjacent level as outcome and other systematic reviews hasn't confirmed the desired effect of cervical spine arthroplasty [3-5].

The main effect of surgery is well accomplished with only discectomy, by decompressing spinal cord and cervical nerve roots under compression. Some previous studies have confirmed the anterior cervical discectomy as the surgery to be performed in cervical spine [2].

In the last decade, anterior cervical discectomy and fusion (ACDF) has gained enormous popularity, been cited as the standard approach after ACD $[1,13]$. The addition of plate was recommended to lower the incidence of extrusion of bone graft after ACDF. In recent times, the development of disc spacers to maintain or enlarge disc space, foramen height and avoid segmental kyphosis after ACD, allowing fusion, has been proposed to be used without vertebral plates, limiting the extent of surgical dissection needed to insert the plates.
This study compared the relative merits of isolated ACD, the use of bone graft in disc space, the use of cage to promote fusion and plate in one level cervical spine disc disease. Among 655 randomized studies in cervical spine, 7 papers compared ACD with the other techniques defined. Five hundred and eighty four patients were randomized ( 6 papers) or quasi-randomised (1 paper), performing the aimed comparison.

The majority of papers used Odom's criteria which provided a mix of healthy status and daily activities limitations. The amount of postoperative Kyphosis and fusion rate were considered the outcomes to be studied in these papers.

Some authors have valorized the fusion rates and pseudoarthrosis rate as influencing clinical outcomes, and kyphosis in cervical spine has been related to painful disorders and progression of adjacent level degeneration in the spine as a whole [13].

Five papers compared ACD with $\mathrm{ACD}$ and the use of autologous bone graft and weren't able to find any difference in clinical outcomes (Odom's) (Fig. 1).

The clinical comparison between ACD and using PMMA as a spacer was not significantly different. Due to the amount of extrusions and complications with PMMA, it hasn't been no longer considered for use in majority of countries.

The comparison between ACD and ACDF with spacers (titanium cage) revealed a greater success rate. The theoretical reasons were enlargement or maintenance of disc height, and prevention of postoperative segmental kyphosis while permitting fusion.

The use of plate in promoting better clinical outcomes (ODOM'S) did not reveal any benefit in only one available paper (Savolainen). 


\section{Fusion Rate Discectomy X Fusion}

Study name Statistics for each study $\quad$ Odds ratio and $95 \% \mathrm{Cl}$

\section{Odds Lower Upper}

ratio limit limit Z-Value $p$-Value

$\begin{array}{llllll}\text { Xie } & 0,143 & 0,014 & 1,509 & -1,618 & 0,106 \\ \text { Barlocher } & 1,107 & 0,146 & 8,392 & 0,098 & 0,922 \\ & 0,464 & 0,100 & 2,156 & -0,980 & 0,327\end{array}$

Favours ACDF Favours ACD

Fig. (4). Comparison between fusion rates between ACD and ACDF. Outcome Odds ratio of fusion rates.

While most disc segment show the evolutes to spontaneous arthrodesis in 4 years, the follow-up in the only paper studied with this outcome did not reveal any difference in the fusion rates between ACD and ACDF.

\section{Implications for Practice}

There is moderate evidence that clinical results of ACD and ACDF are not significantly different.

There is moderate evidence that the addition of intervertebral cage enhances clinical results.

There is moderate evidence that anterior cervical plate does not change the clinical results of ACDF in one cervical spine level.

There is moderate evidence that ACD produce more segmental kyphosis than ACDF and ACDFI, with the use of cage or plate.

There is moderate evidence that ACD produce lower rate of fusion than ACDF and a lower rate than the use of cages.

There is limited evidence of the lower capacity of PMMA to produce fusion.

There is limited evidence that fused patients have a better outcome than non fused patients.

\section{ACKNOWLEDGEMENT}

Declared none.

\section{CONFLICT OF INTEREST}

Declared none.

\section{REFERENCES}

[1] Fraser JF, Härtl R. Anterior approaches to fusion of the cervical spine:a metaanalysis of fusion rates. J Neurosurg Spine 2007; 6: 298-303.

[2] Savolainen S, Rinne J, Hernesniemi J. A prospective randomized study of anterior single-level cervical disc operations with longterm follow-up: surgical fusion is unnecessary. Neurosurgery 1998; 43(1): 51-5.

[3] Bartels RH, Donk R, Verbeek AL. No justification for cervical disk prostheses in clinical practice: a meta-analysis of randomized controlled trials. Neurosurgery 2010; 66(6): 1153-60.

[4] Botelho RV, Moraes OJ, Fernandes GA, Buscariolli Ydos S, Bernardo WM. A systematic review of randomized trials on the effect of cervical disc arthroplasty on reducing adjacent-level degeneration. Neurosurg Focus 2010; 28(6): E5.

[5] Jawahar A, Cavanaugh DA, Kerr EJ III, Birdsong BS, Nunley, PD. Total disc arthroplasty does not affect the incidence of adjacent segment degeneration in cervical spine: results of 93 patients in three prospective randomized clinical trials. Spine J 2010; 10(12): 1043-8.

[6] Tulder M, Furlan A, Bombardier C, Bouter L. Updated method guidelines for systematic reviews in the Cochrane Collaboration Back Review Group. Spine 2003; 28: 1290-9. 
[7] Odom's GL, Finney W, Woodhall B, Durham NC. Cervical disc lesions. JAMA 1958; 166: 23-8.

[8] Xie JC, Hurlbert RJ. Discectomy versus discectomy with fusion versus discectomy with fusion and instrumentation: a prospective randomized study. Neurosurgery 2007; 61(1): 107-16.

[9] Van den Bent MJ, Oosting J, Wouda EJ, Van Acker RE, Ansink BJ, Braakman R. Anterior cervical discectomy with or without fusion with acrylate. A randomized trial. Spine 1996; 21(7):834-9.

[10] Hauerberg J, Kosteljanetz M, Bøge-Rasmussen T, et al. Anterior cervical discectomy with or without fusion with ray titanium cage: a prospective randomized clinical study. Spine 2008; 33(5):458-64.

[11] Rosenørn J, Hansen EB, Rosenørn MA. Anterior cervical discectomy with and without fusion. A prospective study. J Neurosurg 1983; 59(2): 252-5.
[12] Martins AN. Anterior cervical discectomy with and without interbody bone graft. J Neurosurg 1976; 44(3): 290-5.

[13] Bärlocher CB, Barth A, Krauss JK, Binggeli R, Seiler RW. Comparative evaluation of microdiscectomy only, autograft fusion, polymethylmethacrylate interposition, and threaded titanium cage fusion for treatment of single-level cervical disc disease: a prospective randomized study in 125 patients. Neurosurg Focus 2002; 12(1): E4.

[14] Oktenoglu T, Cosar M, Ozer AF, et al. Anterior cervical microdiscectomy with or without fusion. J Spinal Disord Tech 2007; 20(5): 361-8.

[15] Goffin J, Casey A, Kehr P, et al. Preliminary clinical experience with the Bryan Cervical Disc Prosthesis. Neurosurgery 2002; 51(3): $840-5$

(C) Botelho et al.; Licensee Bentham Open.

This is an open access article licensed under the terms of the Creative Commons Attribution Non-Commercial License (http://creativecommons.org/licenses/by-nc/3.0/) which permits unrestricted, non-commercial use, distribution and reproduction in any medium, provided the work is properly cited. 